\title{
Streptococcus milleri pulmonary disease: a review and clinical description of 25 patients
}

\author{
Conroy A Wong, Fiona Donald, John T Macfarlane
}

\begin{abstract}
Background - Streptococcus milleri is increasingly being recognised as an important pulmonary pathogen which may lead to the development of empyema or lung abscess. Although several small series have been reported, the clinical and laboratory features have yet to be fully characterised.

Methods - Twenty five cases were identified and the clinical and laboratory data from case records were analysed.

Results - There were 16 empyemas, five lung abscesses, and four with both lung abscess and empyema. The mean age of the patients was 61 years (range 36-89) and $84 \%$ were men. The most common symptoms at presentation were shortness of breath, chest pain, cough, and weight loss; only $36 \%$ had a fever. Four of the nine patients with lung abscess required a diagnostic lobectomy because of suspected malignancy. Predisposing factors were present in $80 \%$ of patients and included the following: pneumonia, periodontal disease, excess alcohol intake, previous thoracic surgical procedures, and malignancy. Laboratory features of $\boldsymbol{S}$ milleri infection were leucocytosis, neutrophilia, anaemia, abnormal liver function tests, and hypoalbuminaemia. In the group with empyema five patients had a pneumothorax on initial presentation and pleural loculation occurred in $\mathbf{1 0}$ of these patients. The median stay in hospital was 34 days (range 11-88). Six patients died, five of whom had significant underlying illnesses. Conclusions - Pulmonary infection with $S$ milleri may result in considerable morbidity and mortality, and is characterised by a strong male predominance, non-specific symptoms (often without toxicity), the presence of predisposing factors, pleural loculation, pneumothorax, and a protracted stay in hospital.

(Thorax 1995;50:1093-1096)
\end{abstract}

Keywords: Streptococcus milleri, empyema, lung abscess.

Microbiology and

PHLS Laboratory

F Donald

City Hospital,

Nottingham NG5 1PB, UK

Reprint requests to: Dr J T Macfarlane.

Received 24 February 1995 Returned to authors 15 May 1995

Revised version received

26 June 1995

26 June 1995

4 July 1995 system ${ }^{13}$ separates them into distinct species (Streptococcus anginosis, Streptococcus constellatus, Streptococcus intermedius). Two more recent modifications of these systems have been described - one 4 supports a single species (Streptococcus anginosis) and the other ${ }^{56}$ supports a separation into three species. Despite these taxonomic differences, the term "Streptococcus miller" has persisted and is widely used in the clinical setting. Two other terms "viridans streptococci" (which includes other streptococcal species) and "microaerophilic streptococci" - are also used by a number of laboratories to refer to Streptococcus milleri but do not identify the organisms to a species level.

Streptococcus milleri is a widely distributed commensal which is normally found in the mouth, upper respiratory tract, gastrointestinal tract, and vagina. ${ }^{7}$ Various pyogenic infections have been attributed to this pathogen which has a striking predilection for abscess formation. It is a recognised cause of brain, dental, lung, liver, subphrenic, pelvic, and subcutaneous abscesses, as well as abscesses in other sites. It may also cause empyema, meningitis, osteomyelitis, peritonitis, and endocarditis. ${ }^{8-12}$

There are a number of reports documenting the importance of $S$ milleri in the development of empyema and lung abscess. However, only five small series describe the clinical features in these patients. Shlaes et al found six cases of empyema (three associated with lung abscess) and one case of lung abscess alone over a 10 year period. ${ }^{9}$ A series from New Zealand reported four cases of empyema in six months. ${ }^{13}$ Hocken and Dussek ${ }^{14}$ reported six cases of empyema in a consecutive series of 25 patients in one year and Ferber et $a l^{15}$ found 11 patients with empyema in one year and described six cases. Another more recent series from Japan described 10 cases of empyema over a five year period. ${ }^{16}$

We report the characteristics of 25 patients with $S$ milleri infection associated with empyema or lung abscess.

\section{Methods}

Twenty five patients with empyema and/or lung abscess due to $S$ milleri are described. Twenty two cases were identified from the microbiology department computer records of all $S$ milleri specimens from two 1400 bed general hospitals (City and University Hospitals, Nottingham) between October 1991 and September 1994. Three additional patients identified before this period were included in the analysis. Specimens were obtained by thoracocentesis, thoracotomy, and at necropsy in one patient. Med- 
Table 1 Clinical characteristics, management, and outcome in 25 patients with $S$ milleri empyema or lung abscess

\begin{tabular}{|c|c|c|c|c|c|c|c|c|}
\hline $\begin{array}{l}\text { Patient } \\
\text { no }\end{array}$ & $\begin{array}{l}\text { Age } \\
\text { (yrs) }\end{array}$ & Sex & $\begin{array}{l}\text { Abscess }(A) \text { or } \\
\text { empyema }(E)\end{array}$ & Predisposing factors $\dagger$ & $\begin{array}{l}\text { Associated } \\
\text { organisms }\end{array}$ & Treatment $\$$ & $\begin{array}{l}\text { Days in } \\
\text { hospital }\end{array}$ & Outcome \\
\hline 1 & 60 & $\mathbf{M}$ & A & & Nil & Lobectomy & 30 & $\mathbf{R}$ \\
\hline 2 & 89 & M & A & Pneumonia & Nil & & 17 & D \\
\hline 3 & 36 & $\mathbf{M}$ & A & Dental caries and periodontal disease & Nil & Lobectomy & 22 & $\mathbf{R}$ \\
\hline 4 & 42 & M & A & Dental caries and periodontal disease & Nil & Lobectomy $\neq$ & 57 & $\mathbf{R}$ \\
\hline 5 & 64 & M & A & Pneumonia & Nil & Percutaneous catheter drainage & 77 & $\mathbf{R}$ \\
\hline 6 & 51 & $\mathbf{M}$ & $\mathrm{E}$ & Pneumonia, NIDDM, thoracoscopy & Nil & $\begin{array}{l}\text { Intercostal tube drainage, open } \\
\text { drainage + rib resection }\end{array}$ & 27 & $\mathrm{D}$ \\
\hline 7 & 58 & $\mathbf{M}$ & $\mathbf{E}$ & $\begin{array}{l}\text { Spontaneous pneumothorax, } \\
\text { intercostal tube drainage, thoracotomy }\end{array}$ & $\begin{array}{l}\text { Staph aureus } \\
\text { coliform bacilli }\end{array}$ & Intercostal tube drainage & 35 & $\mathrm{R}^{*}$ \\
\hline 8 & 59 & $\mathbf{M}$ & $\mathbf{E}$ & Excess alcohol & Nil & Open drainage + rib resection & 34 & $\mathbf{R}$ \\
\hline 9 & 41 & $\mathbf{M}$ & $\vec{E}$ & Pneumonia & Bacteroides $\mathrm{sp}$ & Open drainage + rib resection & 11 & $\mathbf{R}$ \\
\hline 10 & 49 & $\mathbf{F}$ & $\mathbf{E}$ & Pneumonia, excess alcohol & Anaerobes & Open drainage + rib resection & 41 & $\mathrm{R}$ \\
\hline 11 & 80 & $\mathbf{M}$ & $\bar{E}$ & & Nil & Intercostal tube drainage & 31 & $\mathbf{R}$ \\
\hline 12 & 56 & $\mathbf{M}$ & $\bar{E}$ & Pneumonia, excess alcohol & Nil & Needle aspiration & 11 & $\mathbf{R}$ \\
\hline 13 & 63 & $\mathbf{F}$ & $\mathbf{E}$ & NIDDM & Nil & Open drainage + rib resection & 12 & $\mathbf{R}$ \\
\hline 14 & 73 & $\mathbf{M}$ & $\overline{\mathbf{E}}$ & $\begin{array}{l}\text { Pneumonia, dental caries and } \\
\text { periodontal disease }\end{array}$ & Anaerobes & Intercostal tube drainage & 44 & $\mathrm{D}$ \\
\hline 15 & 64 & $\mathbf{M}$ & $\mathrm{E}$ & $\begin{array}{l}\text { Pharyngeal pouch, aspiration } \\
\text { pneumonia, oral steroids, dental caries } \\
\text { and periodontal disease }\end{array}$ & Bacteroides sp & Intercostal tube drainage & 73 & $\mathrm{R}^{*}$ \\
\hline 16 & 67 & $\mathbf{M}$ & $\mathbf{E}$ & Lung carcinoma, lobectomy & $\begin{array}{l}\text { Coliform } \\
\text { bacilli }\end{array}$ & Intercostal tube drainage & 26 & $\mathrm{D}$ \\
\hline 17 & 83 & $M$ & $\mathrm{E}$ & Oesophageal perforation & $P$ aeruginosa & Intercostal tube drainage & 85 & $\mathbf{R}$ \\
\hline 18 & 77 & $\mathbf{M}$ & $\mathrm{E}$ & Bladder carcinoma & Nil & $\begin{array}{l}\text { Intercostal tube drainage, open } \\
\text { drainage + rib resection }\end{array}$ & 49 & $\mathbf{R}$ \\
\hline 19 & 61 & $\mathbf{M}$ & $\mathbf{E}$ & Pneumonia & $\begin{array}{l}\text { Enterococci, } \\
\text { anaerobes }\end{array}$ & Intercostal tube drainage & 30 & $\mathbf{R}$ \\
\hline 20 & 76 & $\mathbf{M}$ & $\mathrm{E}$ & Pneumonia, stroke & Nil & Antibiotics only & 9 & $\mathrm{D}^{*}$ \\
\hline 21 & 55 & $\mathbf{F}$ & E & Subphrenic abscess & $\begin{array}{l}E \text { coli, } \\
\text { Actinomyces sp, } \\
\text { anaerobes }\end{array}$ & $\begin{array}{l}\text { Needle aspiration, intercostal } \\
\text { tube drainage }\end{array}$ & 88 & $\mathbf{R}$ \\
\hline 22 & 62 & $M$ & E, A & & Nil & Intercostal tube drainage & 36 & $\mathbf{R}$ \\
\hline 23 & 57 & $\mathbf{M}$ & E, A & & Nil & $\begin{array}{l}\text { Lobectomył, open drainage } \\
\text { + rib resection }\end{array}$ & 34 & $\mathbf{R}$ \\
\hline 24 & 44 & $\mathbf{F}$ & $\mathrm{E}, \mathrm{A}$ & $\begin{array}{l}\text { Pneumonia, lung carcinoma, dental } \\
\text { caries and periodontal disease }\end{array}$ & Nil & Intercostal tube drainage & 41 & $\mathrm{D}$ \\
\hline 25 & 52 & $\mathbf{M}$ & $\mathrm{E}, \mathrm{A}$ & & Nil & Intercostal tube drainage & 21 & $\mathbf{R}$ \\
\hline
\end{tabular}

* Admitted to the intensive care unit.

$\dagger$ Pneumonia refers to primary community acquired pneumonia.

$\$$ Diagnostic resection of lung abscess.

$\int$ Not including appropriate antibiotics.

$\mathrm{D}=$ died; $\mathrm{R}=$ recovered; NIDDM $=$ non-insulin dependent diabetes mellitus.

ical records were reviewed using a standard data collection form.

Specimens were directly examined using the Gram stain and then plated onto a range of non-selective and enriched media for aerobic and anaerobic incubation. The plates were incubated at $37^{\circ} \mathrm{C}$ for up to five days. Any colonies with the colonial appearance and typical caramel odour of $S$ milleri were subcultured to check for enhanced growth in carbon dioxide and were Lancefield grouped using a rapid latex test (Oxoid Streptococcal Grouping Kit, Unipath Ltd). The classification scheme of Colman and Williams for viridans streptococci was used. ${ }^{2}$

\section{Results}

Streptococcus milleri pleuropulmonary infection was identified in 25 patients (16 empyemas, five lung abscesses, and four with both lung abscess and empyema). Six patients died. The median age was 60 years (mean 61; range $36-89) ; 21$ of the patients $(84 \%)$ were men.

The median duration of symptoms in 24 of the patients was 18 days (mean 61 ; range 1-300). In addition, one patient (no. 6) had protracted symptoms (730 days) because of difficulty in establishing a diagnosis, and subsequently died. Nine patients had symptoms for more than three months before presentation and only five patients had symptoms for less than one week. The most common symptoms at the time of presentation were shortness of breath $(76 \%)$, chest pain (72\%), cough (64\%), and weight loss $(40 \%)$. Other symptoms included fever (28\%), sweats (16\%), haemoptysis $(12 \%)$, and rigors $(4 \%)$. Twenty patients were cigarette smokers.

Only nine patients had a fever at presentation of $>37.5^{\circ} \mathrm{C}$; however, 20 patients had a fever of $>37.5^{\circ} \mathrm{C}$ during the admission. Clubbing was found in eight patients.

Community acquired pneumonia was associated with the development of empyema or lung abscess in 10 patients (table 1). Dental caries and periodontal disease was noted in four patients; in the other patients this information was not available. Three had a history of excessive alcohol intake. Three patients had previously had thoracic surgical procedures, one patient had a perforated oesophagus which was treated conservatively, and one had a subphrenic abscess. Three patients had carcinomas (two lung, one bladder), two patients had diabetes mellitus, and one had a dense hemiplegia associated with a stroke. One patient was taking oral corticosteroids and no patients were taking other immunosuppressive medications. Overall, a predisposing factor was present in 20 patients.

Streptococcus milleri was grown from pleural fluid (19), resected lung (four), postmortem pleural fluid and lung (one), and lung aspirate (one) in pure culture in 16 of the 25 patients and anaerobic organisms were also cultured in six patients (table 1). Sputum cultures were obtained in 21 patients and $S$ milleri was cultured from only one specimen (pleural fluid positive also). One patient with empyema also 
Table 2 Results of laboratory studies on presentation in 25 patients with $S$ milleri infection

\begin{tabular}{|c|c|c|c|c|}
\hline Test* & Number (\%) & Median & Mean & Range \\
\hline $\begin{array}{l}\text { White cells }\left(\times 10^{9} / 1\right) \\
<11 \\
11-15 \\
>15\end{array}$ & $\begin{array}{r}5(20) \\
9(36) \\
11(44)\end{array}$ & $14 \cdot 5$ & $17 \cdot 1$ & $7 \cdot 3-42 \cdot 3$ \\
\hline$\underset{>7 \cdot 5}{\text { Neutrophils }}\left(\times 10^{9} / 1\right)$ & $19(76)$ & $12 \cdot 8$ & $14 \cdot 2$ & $4 \cdot 3-38 \cdot 6$ \\
\hline $\begin{array}{l}\text { Haemoglobin }(\mathrm{g} / \mathrm{dl}) \\
<13(\mathrm{M}) \text { or }<11 \cdot 5(\mathrm{~F}) \\
<10\end{array}$ & $\begin{array}{r}19(76) \\
7(28)\end{array}$ & $11 \cdot 6$ & $11 \cdot 2$ & $8 \cdot 2-15 \cdot 5$ \\
\hline $\begin{array}{l}\text { ESR (mm/hour) } \\
\text { Urea (mmol/l) } \\
>6.5\end{array}$ & $\begin{array}{l}\text { (6 cases measured) } \\
8(32)\end{array}$ & $\stackrel{96}{5 \cdot 9}$ & $\begin{array}{l}90 \\
9 \cdot 0\end{array}$ & $\begin{array}{l}32-124 \\
3 \cdot 4-29 \cdot 7\end{array}$ \\
\hline$\underset{<30}{\text { Albumin }}(\mathrm{g} / \mathrm{l})$ & $\begin{array}{l}(22 \text { cases measured) } \\
10(45)\end{array}$ & 31 & 30 & $13-45$ \\
\hline
\end{tabular}

* Normal values: white cells 4-11 × 109/1; neutrophils, $2-7.5 \times 10^{9} / 1$; haemoglobin $13-18 \mathrm{~g} / \mathrm{dl}(\mathrm{M})$; $11 \cdot 5-16 \cdot 5 \mathrm{~g} / \mathrm{dl}$ (F); urea, $2-6.5 \mathrm{mmol} / \mathrm{l}$; albumin, $30-48 \mathrm{~g} / 1$.

grew $S$ milleri from a subphrenic abscess. Blood cultures were obtained in all 20 patients who developed a fever of $>37.5^{\circ} \mathrm{C}$ and none grew $S$ milleri. All the $S$ milleri isolates were sensitive to penicillin.

At the time of admission the white cell count was raised in 20 patients ( $80 \%$ ), the neutrophil count was raised in 19 patients $(76 \%)$, and the haemoglobin was low $(<13 \mathrm{~g} / \mathrm{dl} \mathrm{M},<11.5$ $\mathrm{g} / \mathrm{dl} \mathrm{F}$ ) in 19 patients (76\%). Seventeen of the 19 patients $(89 \%)$ in whom liver function tests were measured had abnormal results. Of 22 patients with albumin levels measured at the time of presentation, 10 (45\%) were less than $30 \mathrm{~g} / \mathrm{l}$ (table 2).

Chest radiographs or computed tomographic scans during the hospital admission showed loculation in 10 of the 20 empyemas. Of the 20 empyemas, 13 occurred on the left, as did four of the nine lung abscesses. In five of the empyemas pneumothorax was present on the initial chest radiograph (prior to needle aspiration). Another patient developed empyema complicating spontaneous pneumothorax.

All patients received antibiotics except patient no. 2 in whom the diagnosis was made at necropsy. Patients received a variety of antibiotics because of early empirical treatment; 23 of the 24 patients received benzylpenicillin, ampicillin, amoxycillin, amoxycillin plus clavulanic acid, or cefotaxime following isolation of $S$ milleri. In the group with empyema 13 patients were managed by antibiotics and intercostal tube drainage (table 1) and two patients subsequently required open drainage. Five patients had open drainage as first choice treatment. In the nine patients with lung abscess four had a diagnostic lobectomy and one patient was treated with a percutaneous catheter.

The median duration of stay in hospital for the 19 surviving patients was 34 days (mean 41; range 11-88). Three patients (nos 7, 15, 20) were admitted to the intensive care unit for 24, 35, and nine days respectively. Of the six patients tho died, five had underlying illnesses (two lung cancer), one diabetes, one stroke, one rheumatoid arthritis. Patient no. 2 was diagnosed at necropsy and received no specific treatment. All of the deaths were directly attributed to the underlying $S$ milleri infection. There was no relationship between death and the clinical, laboratory, or radiological features.

\section{Discussion}

Pulmonary infection with $S$ milleri in our series was characterised by a male predominance, leucocytosis, abnormal liver function tests, pleural loculation, a high incidence of pneumothorax, and a protracted stay in hospital. Previous reports have noted the presence of severe toxic symptoms and rapid onset and progression, but these features were not prominent in our cases and the disease was often indolent. ${ }^{1317}$ In four of the nine patients with lung abscess lung resection was performed because malignancy was suspected, and none of these patients had toxic symptoms or fever on presentation.

Predisposing factors which have been associated with $S$ milleri empyema and lung abscess include mucosal disturbance (sinusitis, periodontal disease, enteric disease such as oesophageal perforation), preceding pneumonia, thoracic surgery, malignancy, neurological disease, alcohol abuse, and diabetes. ${ }^{913-17}$ In our series predisposing factors were present in $80 \%$ of cases, with pneumonia occurring in $40 \%$ of the empyemas and thoracic surgery in $15 \%$. This compares with $67 \%$ in an extensive review of $S$ milleri infections at any site. ${ }^{12}$ In empyema caused by other organisms, pneumonia accounted for about $50 \%$ of cases and another $25 \%$ were due to thoracic or gastro-oesophageal surgery. ${ }^{1819}$

Pure culture occurs in $30-83 \%$ of patients with $S$ milleri pleuropulmonary infection and mixed culture with anaerobes in $17-60 \% .{ }^{911} 13-1620 \mathrm{~S}$ milleri was isolated in pure culture in $64 \%$ of our patients and in mixed culture with anaerobes in $24 \%$. These anaerobic organisms, which include Bacteroides, Fusobacterium, Peptostreptococcus, and Prevotella, are members of the oral flora and their presence in association with $S$ milleri infections suggests an oropharyngeal source of infection. They may also have a role in promoting $S$ milleri infection by delaying clearance, enhancing growth, and inhibiting bactericidal activity of neutrophils. ${ }^{21}$ Although the pathogenic mechanisms involved in $S$ milleri infections have yet to be fully elucidated, $S$ milleri is known in some isolates to produce enzymes such as hyaluronidase, DNase, gelatinase, collagenase, and an immunosuppressant substance..$^{22-25} \mathrm{An}$ aerobic organisms may also produce extracellular enzymes and it has been proposed that these could act in concert with enzymes produced by $S$ milleri in causing tissue damage and spread of infection. ${ }^{21}$

The characteristic features of pleuropulmonary disease caused by $S$ milleri do not reliably distinguish it from pleuropulmonary disease due to other organisms. In a review of series of empyema reported between 1980 and 1991 the most common predisposing factor was pneumonia, the average hospital stay varied between 12 and 56 days, and mortality ranged from 0 to $51 \% .{ }^{26}$ Several differences, however, can be noted. Firstly, in empyema due to $S$ milleri pleural loculation is common while loculation occurs rarely in pneumococcal empyema. $^{26}$ Secondly, the high incidence of pneumothorax noted in our series is unusual, 
and suggests that empyema arose by rupture of a peripheral lung abscess.

The key principles of management of $S$ milleri infection are early diagnosis, control of the infection with appropriate antibiotics, and adequate drainage. During the assessment of patients it is important to be aware that toxic symptoms may be absent and that lung abscess may mimic malignancy. Periodontal disease appears to be an important predisposing factor which may be underestimated and all patients should have a careful examination of the mouth and teeth. The antibiotic of choice is intravenous penicillin, although the organism is also susceptible to ampicillin and cephalosporins. For patients allergic to penicillin, suitable alternatives are erythromycin, clindamycin, or vancomycin. ${ }^{12}$ If empirical treatment is necessary, metronidazole should be added to cover for anaerobic organisms. For empyema, drainage is usually achieved by closed methods but open surgical drainage may be required and often represents chest tube failure or delayed presentation. The principle of early space drainage in the management of empyema has been questioned in a recent study. ${ }^{27}$ However, no cases of $S$ milleri were reported in the study and further evidence is required before delaying or withholding drainage. Recently there has been increased interest in the use of intrapleural streptokinase to facilitate drainage and, with the development of purer formulations, this appears to be safe and effective. ${ }^{2829}$ This form of treatment may be particularly suitable for $S$ milleri infections because of the frequent occurrence of loculation.

Although the incidence of empyema or lung abscess caused by $S$ milleri is low, infection is associated with considerable morbidity and mortality. Patients often have a complicated course in hospital and may consume considerable resources during their management. It is therefore important that patients are managed aggressively with a view to early and accurate diagnosis, antibiotics, and appropriate drainage.

1 Facklam RR. The major differences in the American and British streptococcus taxonomy schemes with special reference to Streptococcus milleri. Eur f Clin Microbiol 1984; 3:91-3.

2 Colman G, Williams REO. Taxonomy of some human viridans streptococci. In: Wannamaker LW, Matsen JM, eds. Streptococci and streptococcal diseases: recognition, understanding, and
3 Facklam RR. Physiological differentiation of viridans streptococci. $\mathcal{f}$ Clin Microbiol 1977;5:184-201.

4 Coykendall AL, Wesbecher PM, Gustafson KB. Streptococcus milleri, Streptococcus constellatus, and Streptococcus intermedius are later synomyms of Streptococcus anginosis. Int $\mathcal{F}$ System Bacteriol 1987;37:222-8.

5 Whiley RA, Fraser H, Jardie JM, Beighton D. Phenotypic differentiation of Streptococcus intermedius, Streptococcus constellatus and Streptococcus anginosis strains within the Streptococcus milleri group. F Clin Microbiol 1990;28:1497Streptoco 501 .

6 Whiley RA, Beighton D. Amended descriptions and recognition of Streptococcus constellatus, Streptococcus intermedius and Streptococcus anginosus as distinct species. In f System Bacterol 1991;41:1-5.

7 Poole PM, Wilson G. Occurrence and cultural features of Streptococcus milleri in various body sites. $\mathcal{F}$ Clin Pathol 1979;32:764-8.

8 Murray HW, Gross KC, Masur H, Roberts RB. Serious infections caused by Streptococcus milleri. Am $\mathcal{F}$ Med 1978; 64:759-64.

9 Shlaes DM, Lerner PI, Wolinsky E, Gopalakrishna KV. Infections due to Lancefield group $\mathrm{F}$ and related strep-
tococci $(S$ milleri, $S$ anginosis). Medicine 1981;60:197-207.

tococci (S miller, S anginosis). Medicine 1981;60:197-207.
10 Van der Auwera P. Clinical significance of Streptococcus milleri. Eur $\mathcal{f}$ Clin Microbiol 1985;4:386-90.

11 Singh KP, Morris A, Lang SDR, MacCulloch DM, Bremner DA. Clinically significant Streptococcus anginosus (Streptococcus milleri) infections: a review of 186 cases. NZ Med f 1988;101:813-6.

12 Gossling J. Occurrence and pathogenicity of the Streptococcus milleri group. Rev Infect Dis 1988;10:257-85.

13 Frankish PD, Kolbe J. Thoracic empyema due to Streptococcus milleri: four cases. NZ Med $尹$ 1984;97:849-51.

14 Hocken DB, Dussek JE. Streptococcus milleri as a cause of pleural empyema. Thorax 1985;40:626-8.

15 Ferber Th, Muller F, Graevenitz Av. Pleuraempyeme mit Streptococcus milleri. Schweiz Med Wschr 1987;117:916-9.

16 Shinzato T, Uema H, Inadome J, Shimoji K, Kusano N, Shinzato $\mathrm{T}$, Uema $\mathrm{H}$, Inadome J, Shimoji $\mathrm{K}$, Kusano $\mathrm{N}$,
Fukuhara $\mathrm{H}$, et al. Bacteriological and clinical studies in 23 cases of thoracic empyema: the role of oral streptococci 23 cases of thoracic empyema: the role of oral streptococci and anaerobes.

17 Roy WJ Jr, Roy TM. Thoracic empyema due to Streptococcus intermedius. Kentucky Med Assoc $¥$ 1991;89:558-62.

18 Moores DWO. Management of acute empyema. Chest 1992; 102:1316-7.

19 Benfield GFA. Recent trends in empyema thoracis. $\mathrm{Br} \mathcal{F} \mathrm{Di}$ Chest 1981;75:358-66.

20 Waitkins SA, Ratcliffe JG, Roberts C. Streptococcus milleri found in pulmonary empyemas and abscesses [letter]. $\mathscr{F}$ Clin Pathol 1985;38:716-7.

21 Shinzato T, Saito A. A mechanism of pathogenicity of "Streptococcus milleri group" in pulmonary infection: syn"Streptococcus miller group" in pulmonary infection: synergy with an anaerobe. $\mathcal{F}$ Med Microbiol 1994;40:118-23.
22 Unsworth PF. Hyaluronidase production in Streptococcus milleri in relation to infection. $\mathcal{F}$ Clin Pathol 1989;42:
molth PF. Hyaluronidase production in Streptococus milleri in

23 Steffen EK, Hentges DJ. Hydrolytic enzymes of anaerobic bacteria isolated from human infections. $\mathcal{f}$ Clin Microbiol 1981;14:153-6.

24 Marshall R, Kauffman AK. Production of deoxyribonuclease, ribonuclease, coagulase, and hemolysins by anaerobic gram-positive cocci. F Clin Microbiol 1981;13: 787-8.

25 Ruoff KL, Ferraro MJ. Hydrolytic enzymes of "Streptococcus miller". F Clin Microbiol 1987;25:1645-7.

26 Strange C, Sahn SA. Management of parapneumonic pleural effusions and empyema. Infect Dis Clin North Am 1991;5: 539-59.

27 Berger HA, Morganroth ML. Immediate drainage is not required for all patients with complicated parapneumonic required for all patients with complions. Chest 1990;97:731-5.
effusions

28 Bouros D, Schiza S, Panagou P, Drositis J, Siafakas N. Role of streptokinase in the treatment of acute loculated parapneumonic pleural effusions and empyema. Thorax 1994;49:852-5.

29 Taylor RFH, Rubens MB, Pearson MC, Barnes NC. Intrapleural streptokinase in the management of empyema. Thorax 1994;49:856-9. 